\title{
Effects of format on the distribution of scores on the Vividness of Visual Imagery Questionnaire: A replication and extension
}

\author{
STUART J. MCKELVIE \\ Bishop's University, Lennoxville, Quebec, Canada
}

\begin{abstract}
One hundred ninety-three undergraduates completed the Vividness of Visual Imagery Questionnaire (VVIQ) in the original (blocked) version or in a random format. Variances were unaffected, but as in previous research, mean scores were higher for the random version, indicating reports of less vivid imagery. Although these data do not show that the distribution of scores on the random version provided a psychometric improvement over that of the blocked VVIQ, they offer some hope to researchers seeking to study "poor" visualizers.
\end{abstract}

In cognitive psychology research, the most popular measure of individual differences in visual imagery is Marks's (1973) Vividness of Visual Imagery Questionnaire (VVIQ), which has been employed in over 100 investigations (Marks, 1989). Respondents rate 16 items arranged in four blocks of four on a 5-point scale of vividness: (1) "Perfectly clear and as vivid as normal vision," (2) "Clear and reasonably vivid," (3) "Moderately clear and vivid," (4) "Vague and dim," and (5) "No image at all." However, it has been observed that the distribution of scores is positively skewed, with a mean between 2 and 2.5 (Chara \& Hamm, 1989; Kihlstrom, Glisky, Peterson, Harvey, \& Rose, 1991; McKelvie, 1979, 1986; Sommer, 1980). This implies that the full range of imagery ability is not captured and that a truncated variance may weaken correlations with other variables (Kihlstrom et al., 1991). The mean score for subjects classified as "good" imagers is approximately 1.5 (McKelvie, 1979), indicating that it may be easy to find subjects who report imagery that is extremely vivid (e.g., Wallace, 1984; Wallace, Persanyi, \& Gerboc, 1989). However, the corresponding score for subjects classified as "poor" imagers is usually between 2.4 and 2.9 (Kihlstrom et al., 1991; McKelvie, 1986), indicating that they are reporting imagery that is moderate to clear.

It has been suggested that the blocked format of the VVIQ, like that of its parent, Sheehan's (1967) revision of the Betts' Questionnaire Upon Mental Imagery, encourages a lenient response bias (McKelvie, 1986, 1990). In support of this view, it has been found that ratings on both questionnaires were higher, that is, less vivid, when the items were randomized (McKelvie, 1986; White, Ashton, \& Law, 1978). Although there was no effect of format in an earlier study with the VVIQ (McKelvie, 1979), it was given in a nonstandard fashion with a vari-

Send reprint requests to S. J. McKelvie, Department of Psychology, Bishop's University, Lennoxville, PQ J1M 1Z7, Canada. ety of instructions. The purpose of this experiment is to replicate the effect of format on general mean scores and to examine its effect on variances and on the mean scores of "good" and "poor" visualizers. If the random distribution shifts upward on the scale, it may become less positively skewed or even normal, particularly if the mean reaches the midpoint. This would allow the scale to meet the usual psychometric requirements (Kihlstrom et al., 1991). In either case, the variance of the random distribution may be greater than that of the blocked distribution, thereby alleviating the problem of restriction in range.

\section{METHOD}

\section{Subjects}

One hundred ninety-three undergraduate volunteers (66 males, 127 females) were assigned to the blocked and random experimental conditions, with matching for gender (see Table 1).

\begin{abstract}
Materials and Procedure
Each subject was tested individually by one of two experimenters. Care was taken to ensure that the polarity of the rating scale was understood, since Marks (1983, p. 108) mentions that some individuals reverse it. In their own time, the subjects completed either Marks's (1973) original VVIQ, in which the items were presented in blocks, or a new version (McKelvie, 1986), in which the items were randomly reordered with the restriction that no two successive ones came from the same block. Marks (1983, p. 108) recommends that the VVIQ be administered twice, once with eyes open and once with eyes closed. However, since Dowling (cited in White, Sheehan, \& Ashton, 1977, p. 146) indicates that the reason for this is unclear and that it does not seem to influence test scores, the questionnaire was given only once, with no mention of eyes. Although the subjects were given the opportunity for personal feedback on their own scores, they were unaware that there were two test formats or even another experimental condition.
\end{abstract}

\section{RESULTS AND DISCUSSION}

From Table 1, it can be seen that the score distributions were positively skewed in both cases, although less severely with the random VVIQ. A $2 \times 2$ (format $\times$ gender) analysis of variance (ANOVA) showed that ratings were higher with the random $(M=2.43)$ than with 
Table 1

Distributions of VVIQ Scores for Blocked and Random Formats: Number and Percentage of Cases in Each Class Interval

\begin{tabular}{|c|c|c|c|c|c|c|c|c|c|}
\hline \multirow[b]{2}{*}{ Format } & \multicolumn{9}{|c|}{ VVIQ Class Interval } \\
\hline & $n$ & 1 & 2 & 3 & 4 & 5 & 6 & 7 & 8 \\
\hline \multicolumn{10}{|l|}{ Blocked } \\
\hline Males & 31 & 2 & 11 & 11 & 3 & 2 & 1 & 0 & 1 \\
\hline Females & 59 & 8 & 17 & 18 & 8 & 6 & 1 & 1 & 0 \\
\hline Total & 90 & 10 & 28 & 29 & 11 & 8 & 2 & 1 & 1 \\
\hline Percentage & & 11.1 & 31.1 & 32.2 & 12.2 & 8.9 & 2.2 & 1.1 & 1.1 \\
\hline \multicolumn{10}{|l|}{ Random } \\
\hline Males & 35 & 4 & 5 & 12 & 7 & 4 & 2 & 0 & 1 \\
\hline Females & 68 & 2 & 16 & 21 & 15 & 9 & 5 & 0 & 0 \\
\hline Total & 103 & 6 & 21 & 33 & 22 & 13 & 7 & 0 & 1 \\
\hline Percentage & & 5.8 & 20.4 & 32.0 & 21.4 & 12.6 & 6.8 & 0.0 & 1.0 \\
\hline
\end{tabular}

Note-The score boundaries for the class intervals from 1 to 8 were as follows: $1.0-1.4,1.5-1.9$, 2.0-2.4, 2.5-2.9, 3.0-3.4, 3.5-3.9, 4.0-4.4, and 4.5-5.0.

Table 2

Means, Variances, and Ranges for VVIQ Scores in Each Condition

\begin{tabular}{|c|c|c|c|c|c|c|c|c|}
\hline Format & $n$ & $\boldsymbol{M}$ & $s^{2}$ & Range & $n$ & $M$ & $s^{2}$ & Range \\
\hline & \multicolumn{4}{|c|}{ Men } & \multicolumn{4}{|c|}{ Women } \\
\hline $\begin{array}{l}\text { Blocked } \\
\text { Random }\end{array}$ & $\begin{array}{l}31 \\
35\end{array}$ & $\begin{array}{l}2.23 \\
2.42\end{array}$ & $\begin{array}{l}0.54 \\
0.61 \\
\text { od }\end{array}$ & $\begin{array}{l}19-80 \\
19-80\end{array}$ & $\begin{array}{l}59 \\
68\end{array}$ & $\begin{array}{l}2.14 \\
2.44\end{array}$ & $\begin{array}{l}0.42 \\
0.40 \\
\text { or }\end{array}$ & $\begin{array}{l}16-66 \\
21-63\end{array}$ \\
\hline $\begin{array}{l}\text { Blocked } \\
\text { Random }\end{array}$ & $\begin{array}{l}25 \\
29 \\
\end{array}$ & $\begin{array}{l}1.46 \\
1.70 \\
\end{array}$ & $\begin{array}{l}0.05 \\
0.06\end{array}$ & $\begin{array}{l}16-28 \\
19-32 \\
\end{array}$ & $\begin{array}{l}25 \\
29\end{array}$ & $\begin{array}{l}3.01 \\
3.29 \\
\end{array}$ & $\begin{array}{l}0.34 \\
0.22 \\
\end{array}$ & $\begin{array}{l}40-80 \\
44-80 \\
\end{array}$ \\
\hline
\end{tabular}

Note-Maximum score $=5.0$ (no image) .

the blocked $(M=2.17)$ version $[F(1,189)=5.47, p<$ $.05]$ (see Table 2). The standardized size of the effect ( $d$; Cohen, 1977) was 0.40. However, it can be seen that format had no significant effect on the variances or ranges for either men $[F(30,34)=1.13, p>.10]$ or women $[F(58,67)=1.07, p>.10]$.

These results replicate McKelvie's (1986) finding that imagery was reported to be less vivid with the random $(M=2.35)$ than with the blocked $(M=2.14)$ VVIQ, providing further evidence that the original format may encourage lenient responding. At the same time, the distribution of scores for the random test remained positively skewed, with a mean of 2.43 within the general range previously found for the blocked version $(2-2.5)$, and the size of the format effect was, in Cohen's (1977, pp. 2526) terms, only "small" to "medium." In addition, variances on the random test did not increase, as had been hoped. In fact, in both cases, one male obtained the maximum score. However, this was not associated with a significant effect of gender, adding to previous mixed results showing either no difference (Narchal \& Broota, 1988; Richardson, 1979) or higher reports of visual imagery vividness for females (Crawford, 1982; McKelvie, $1984,1986)$. Since the random distribution was not normal, had a mean below 3 , and had a variance similar to that of the blocked distribution, the random VVIQ did not provide an overall psychometric improvement to the original version.

To avoid the problem that weak correlations might be due to low variance, Kihlstrom et al. (1991) recommended the method of extreme groups, in which "good" and "poor" visualizers are compared on a criterion task. However, in their own data, the mean score for "poor" visualizers, based on a quartile split, was 2.44 , which they regard as unsatisfactory. The implications of the present data for this issue were examined by forming such groups from each experimental distribution using the optimal $27 \%$ rule (Feldt, 1961). Data for males and females were split but combined for the $2 \times 2$ (format $\times$ ability) ANOVA. Scores were higher for the random than for the blocked VVIQ $[F(1,104)=11.05, p<.01]$ and, of course, for the poor than for the good visualizers $[F(1,104)=$ 408.63, $p<.01$ ]. The most interesting aspect of these results is the mean score of 3.29 for the poor visualizers on the random test (see Table 2). In contrast to previous reports and to the present score for the blocked version, it was higher than 3 . Although remaining below $4[t(29)=$ $8.20, p<.01]$, it offers some hope to researchers hoping to answer Marks's (1973, p. 17) initial question (bracketed comments and emphases mine): "In what ways, if any, does the recall of a man who states that his imagery is clear and vivid [i.e., a rating of 1 to 2] differ from another who reports imagery that is vague and dim [i.e., a rating of 4 ]?"

\section{REFERENCES}

Chara, P. J., Hamm, D. A. (1989). An inquiry into the construct validity of the Vividness of Visual Imagery Questionnaire. Perceptual \& Motor Skills, 63, 915-920.

COHEN, J. (1977). Statistical power analysis for the behavioral sciences (rev. ed.). New York: Academic Press.

CRAWFORD, H. J. (1982). Hypnotizability, daydreaming styles, imag- 
ery vividness, and absorption: A multidimensional study. Journal of Personality \& Social Psychology, 42, 915-926.

FeLDT, L. S. (1961). The use of extreme groups to test for the presence of a relationship. Psychometrika, 26, 307-316.

Kinlstrom, J. F., Guisky, M. L., Peterson, M. Q., Harvey, E. M., \& Rose, P. M. (1991). Vividness and control of imagery: A psychometric analysis. Journal of Mental Imagery, 15, 133-142.

MARKs, D. F. (1973). Visual imagery differences in the recall of pictures. British Journal of Psychology, 64, 17-24.

Marks, D. F. (1983). Mental imagery and consciousness: A theoretical review. In A. A. Sheikh (Ed.), Imagery: Current theory, research, and application (pp. 96-130). New York: Wiley.

MARKs, D. F. (1989). Construct validity of the Vividness of Visual Imagery Questionnaire. Perceptual \& Motor Skills, 69, 459-465.

McKelVIE, S. J. (1979). Effects of instructions and format on reported visual imagery. Perceptual \& Motor Skills, 49, 567-571.

MCKelviE, S. J. (1984). Reported visual imagery for faces and facial recognition memory. Perceptual \& Motor Skills, 59, 825-826.

MCKelvie, S. J. (1986). Effects of format of the Vividness of Visual Imagery Questionnaire on content validity, split-half reliability, and the role of memory in test-retest reliability. British Journal of Psychology, 77, 229-236.

McKelvie, S. J. (1990). The Vividness of Visual Imagery Questionnaire: Commentary on the Marks-Chara debate. Perceptual \& Motor Skills, 70, 551-560.
Narchal, R., \& Broota, K. D. (1988). Sex differences in vividness of visual imagery under eyes open and closed conditions. Journal of Mental Imagery, 12, 81-88.

RichARDSON, A. (1979) Dream recall frequency and vividness of visual imagery. Journal of Mental Imagery, 3, 65-72.

Sheehan, P. W. (1967). A shortened form of the Betts' Questionnaire Upon Mental Imagery. Journal of Clinical Psychology, 23, 386-389.

SOMmer, R. (1980). Strategies for imagery research. Journal of Mental Imagery, 4, 115-121.

WallaCE, B. (1984). Creation of the horizontal-vertical illusion through imagery. Bulletin of the Psychonomic Society, 22, 9-11.

Wallace, B., Persanyi, M. W., Gerboc, B. (1989). Imagery, hypnosis and the creation of subjective contours. Journal of Mental Imagery, 13, 139-152.

White, K. D., Ashton, R., LAW, H. (1978). The measurement of imagery vividness: Effects of format and order on the Betts' Questionnaire Upon Mental Imagery. Canadian Journal of Behavioural Science, 10, 68-78.

White, K. [D.], Sheehan, P. W., \& Ashton, R. (1977). Imagery assessment: A survey of self-report measures. Journal of Mental Imagery, 1, 145-170.

(Manuscript received February 24, 1992.)

\section{Seventh International Conference on Event Perception and Action Vancouver, B.C., Canada August 8-13,1993}

The International Society for Ecological Psychology and the Psychology Department of the University of British Columbia are sponsoring the Seventh International Conference on Event Perception and Action to be held at the Conference Centre on the University of British Columbia campus.

This conference will present paper and poster sessions on a wide variety of topics, including, but not limited to, ecological acoustics, perceptual and cognitive development, perceptual guidance of locomotion, analysis of intentional systems, and ecological approaches to social psychology.

To have your name placed on the mailing list for the call for papers or for further information, contact John B. Pittenger, Department of Psychology, University of Arkansas at Little Rock, 2801 South University Avenue, Little Rock, AR 72204 (telephone 501-569-3171, e-mail icepa7@ualr.edu). 